\title{
Estudos culturais: possibilidades para pensar de outro modo a pesquisa em enfermagem
}

\author{
Cultural studies: new perspectives on research possibilities in nursing \\ Estudios culturales: posibilidades para pensar de otra manera la investigación \\ en enfermería
}

\author{
Maria Henriqueta Luce Kruse ${ }^{a}$ \\ Carla da Silveira Dornelles ${ }^{a}$ \\ Kelly Ribeiro de Freitas Viana ${ }^{a}$ \\ Kiciosan da Silva Bernardia \\ Mariane da Silva Xavier Botega ${ }^{a}$ \\ Monalisa da Silva Pinheiro
}

\section{Como citar este artigo:} Kruse MHL, Dornelles CS, Viana KRF, Bernardi KS, Botega MSX, Pinheiro MS. Estudos culturais: possibilidades para pensar de outro modo a pesquisa em enfermagem. Rev Gaúcha Enferm. 2018;39:e2017-0135. doi: https://doi. org/10.1590/1983-1447.2018.20170135
Universidade Federal do Rio Grande do Sul (UFRGS), Escola de Enfermagem. Porto Alegre, Rio Grande do Sul, Brasil.

\section{RESUMO}

Objetivo: Refletir sobre as possibilidades de pesquisa na Enfermagem, sobretudo no campo dos Estudos Culturais.

Metodologia: Estudo teórico-reflexivo, baseado em pesquisas desenvolvidas na ótica dos Estudos Culturais que realizam uma possivel articulação com alguns aspectos do pensamento do filósofo Michel Foucault.

Resultados: Expõe as produções do Grupo de Estudos Culturais na Educação em Saúde e Enfermagem da Universidade Federal do Rio Grande do Sul.

Palavras finais: Os Estudos Culturais, como campo transdisciplinar, possibilita refletir sobre a constituiç̧ão do sujeito e sua relação com as demandas culturais de uma época. Aponta a possibilidade de tal referencial teórico na área da saúde, especialmente na Enfermagem.

Palavras-chave: Enfermagem. Filosofia em Enfermagem. Cultura. Educação. Metodologia.

\section{ABSTRACT}

Objective: To reflect on the research possibilities in nursing, especially in the field of cultural studies.

Methods: Theoretical-reflexive study based on research from the perspective of cultural studies and some aspects of the thoughts of Michel Foucault

Results: The results expose research conducted by the Group of Cultural Studies in Health and Nursing Education of the Universidade Federal do Rio Grande do Sul.

Final words: Cultural Studies, as a trans-disciplinary field, allow reflection on the constitution of subjects and their relationship with the cultural demands of an era. As a theoretical framework, it can be used for the study of healthcare, especially nursing. Keywords: Nursing. Philosophy in Nursing. Culture. Education. Methodology.

\section{RESUMEN}

Objetivo: Reflexionar sobre las posibilidades de investigación en la enfermería, sobre todo en el campo de los estudios culturales. Metodología: Estudio teórico-reflexivo, basado en investigaciones desarrolladas en la óptica de los Estudios Culturales que realizan una posible articulación con algunos aspectos del pensamiento del filósofo Michel Foucault

Resultados: Expone la producción del Grupo de Estudios Culturales en la Educación en Salud y Enfermería, vinculado a la Universidad Federal de Rio Grande do Sul.

Palabras finales: Los estudios culturales como campo transdisciplinario que posibilita una reflexión sobre la constitución de los sujetos y su relación con las demandas culturales de una época, apuntando a la posibilidad de tal referencial teórico a cuestiones del área de la salud, especialmente de la enfermería.

Palabras clave: Enfermería. Filosofía en Enfermería. Cultura. Educación. Metodología. 


\section{PALAVRAS INICIAIS}

Cultura é um conceito complexo, com sentidos nas diferentes línguas, impossível de ser fixado. Assim, uma das possibilidades de entender tal conceito seria qualificá-lo como o conjunto das manifestações humanas, em contraste com a natureza. Vulgarmente costuma ser associada à aquisição de conhecimentos e práticas de vida reconhecidas como melhores, superiores. Tal sentido geralmente se associa ao que é descrito como alta cultura, em oposição à cultura de massa percebida como expressão e manifestação esteticamente inadequada e sem relevância. Nos séculos XVIII, XIX e XX, a alta cultura era entendida como detentora de harmonia e beleza, como a máxima expressão humana, em oposição a cultura de massa, vista como trivial e simplificada. Neste cenário, os Estudos Culturais surgem em meio a manifestações de determinados grupos sociais que desejavam uma cultura sustentada em oportunidades democráticas ${ }^{(1)}$.

Os Estudos Culturais como campo de investigação iniciaram após a Segunda Guerra Mundial tendo como marco conceitual o texto "Schools of English and Compemporary Society" de Richard Hoggart, o primeiro diretor do Center for Comtemporary Cultural Studies (CCCS) da Universidade de Birmingham ${ }^{(2)}$ que descrevia sobre os antecedentes históricos e a contribuição para o estudo da cultura e da comunicação do século XX. Foram considerados inovadores, pois visavam relatar os modos de vida da classe operária da Grã-Bretanha. Tais estudos estavam alicerçados na compreensão das relações sociais e no importante papel da comunicação na produção da cultura ${ }^{(2)}$. Os Estudos Culturais estão presentes nas instituições acadêmicas em atividades vinculadas às ciências literárias, humanas, sociologia, artes e também na saúde. Caracterizam-se por possibilitar diferentes posições teóricas e políticas que partilham do compromisso de analisar práticas culturais do ponto de vista das relações de poder. Deste modo, os campos teóricos mais frequentemente utilizados abrangem desde 0 marxismo e o feminismo, a psicanálise, o estruturalismo e o pós-estruturalismo, até o pós-modernismo ${ }^{(3-4)}$.

Nessa perspectiva, os Estudos Culturais não tem metodologia distinta, análise estatística específica, ou mesmo uma análise que possa chamar de sua, que caracterize seus estudos. Seus métodos são ambíguos e podem ser considerados uma bricolagem. Por isso, os delineamentos relacionados ao conceito de cultura transpõem os eixos da erudição, das tradições artísticas ou de sua hierarquia, abrindo um leque de sentidos amplos e versáteis para o tema. Abandona-se o pressuposto elitista privilegiando a adoção de leituras das populações e do senso comum, já que para os Estudos Culturais o conhecimento está na justaposição da trama de ideias e nas relações políticas e sociais ${ }^{(4-5)}$. Desse modo, se nossas maneiras de perceber o mundo são culturalmente construídas, pode-se pensar que os significados atribuídos à saúde, ao corpo, a morte, a ser enfermeiro ou a dor, também podem ser moldados na cultura. No Brasil, os Estudos Culturais se estabeleceram em meados de 1990 e o Programa de Pós-Graduação em Educação da Universidade Federal do Rio Grande do Sul (UFRGS) um dos lugares em que se organizaram, especialmente através de textos que foram discutidos por professores e alunos, para utilização do referencial em seus trabalhos de pesquisa. Tal programa possibilitou a emergência destes estudos em diferentes áreas do conhecimento, tanto na UFRGS como fora dela. Neste contexto, em 2008, foi criado o Grupo de Estudos Culturais na Educação em Saúde e Enfermagem (CULT), vinculado a Escola de Enfermagem e ao Programa de Pós-Graduação em Enfermagem da UFRGS. O objetivo deste artigo é refletir sobre esta maneira de construir o conhecimento, bem como registrar e apresentar possibilidades de pesquisa na área da saúde, especialmente da Enfermagem, na perspectiva dos Estudos Culturais ${ }^{(5)}$. Para isso, elaboramos este estudo teórico-reflexivo, que aborda pesquisas desenvolvidas em nosso grupo, na ótica dos Estudos Culturais, apontando suas possibilidades na área de enfermagem.

\section{IESTUDOS CULTURAIS: POSSIBILIDADES NA ENFERMAGEM E SAÚDE}

Os Estudos Culturais levam a pensar como artefatos culturais: tais como imagens e reportagens, educam as pessoas, produzindo novos modos de pensar e fazer. No que se refere ao campo da saúde, permitem que "todas as práticas" sociais possam ser examinadas de um ponto de vista cultural(2). Isso quer dizer que ações sociais são significativas tanto para quem pratica quanto para quem observa. Ou seja, o ser humano utiliza diversos sistemas para dar significado às coisas, bem como para organizar e regular sua conduta em relação aos outros. Tais sistemas conduzem nosso modo de viver, dão sentido às nossas ações e nos permitem interpretar as ações dos outros. Tais sistemas ou códigos em conjunto instituem nossas "culturas". Desse modo, se pode dizer que toda a ação social é "cultural"(4).

Os Estudos Culturais permitem o rompimento com as metanarrativas da modernidade (das elites, dos vencedores, da família modelo, das grandes obras, entre outros) e com as certezas impostas como verdades pelo paradigma positivista. Na perspectiva dos Estudos Culturais, as verdades, percebidas como construções históricas, são coloca- 
das sob suspeita. As formações culturais contemporâneas, os deslocamentos no cenário político, econômico, no arranjo familiar, no estilo de vida, nos padrões de diferenças de gerações, na visão social do homem e da mulher, no envelhecimento da população, compõem um cenário próprio para o desenvolvimento de pesquisas nessa perspectiva. As análises realizadas nessa vertente entendem que os sujeitos são resultados de suas culturas, ou seja, a cultura produz os sujeitos em um determinado momento histórico, o que nos permite analisar como chegamos a ser como somos hoje, oferecendo base teórica para promover desconstruções necessárias para estudos no âmbito da saúde ${ }^{(6-7)}$. Neste âmbito, destacamos a Enfermagem que a partir do modelo biomédico introduzido por Florence Nightingale (séc. XIX) se reconhece como ciência( ${ }^{(8)}$. Este modelo é caracterizado pela relação entre enfermeira-paciente apoiada em protocolos prescritivos de cuidado e indicadores de produtividade da assistência. Apesar desta perspectiva moderna e positivista da organização profissional da Enfermagem, a enfermeira transita em outras ciências como a sociologia, a antropologia e a pedagogia, permitindo novas possibilidades de pensar seus problemas e questões profissionais ${ }^{(9)}$.

Realizando uma possível articulação entre os Estudos Culturais e alguns aspectos do pensamento do filósofo Michel Foucault, voltamos nossa atenção para uma das lições da virada linguística: os significados não existem soltos no mundo, a espera de serem desvelados. Enquanto coisa deste mundo existem a partir do momento que são enunciados. Já os discursos não são combinações de palavras que representariam as coisas do mundo, são "práticas que formam sistematicamente os objetos de que falam"(10:56). Os discursos podem ser entendidos como histórias, que articuladas entre si se apresentam para nós como verdades. Tais regimes de verdade vão estabelecer os modos de pensar, de tal modo que fora desse campo de possibilidades não terão sentido. Tais redes discursivas instituem um conjunto de significados que, ao longo do tempo, irão funcionar no âmbito simbólico, através do qual daremos sentidos às nossas vidas( ${ }^{(6)}$. Portanto, dar sentido às coisas nos faz uma espécie cultural. A questão é olhar para a cultura e pensar como damos significados aos objetos e as práticas. Ao fazermos isso, transferimos tais significados para diferentes contextos e os ressignificamos.

\section{Pesquisas do Grupo de Estudos Culturais na Educação em Saúde e Enfermagem}

Ensaios e pesquisas constituem as produções do Grupo de Estudos Culturais na educação em saúde e enferma- gem (CULT), geralmente, sob a forma de dissertações e teses. O grupo reúne pesquisadoras da área da Enfermagem que realizam análises culturais no campo da educação em saúde e enfermagem, no panorama dos Estudos Culturais contemporâneos na perspectiva pós-estruturalista com ênfase em Michel Foucault.

As principais pesquisas desenvolvidas pelo CULT utilizam como corpus de análise filmes, internet, jornais e revistas, fotografias, manuais de políticas públicas e outros artefatos culturais com diferentes metodologias e técnica de pesquisas como análise de discurso, análise documental, grupo focal, etnografia, entrevista e história oral, que constituem formas de compreensão das relações e práticas sociais, especialmente daquelas que tratam da enfermagem e da saúde. Os resultados de tais pesquisas estão publicados em periódicos nacionais e internacionais no âmbito da Enfermagem, da Educação, das Ciências Sociais e da Saúde Coletiva. A seguir, apresentamos algumas produções no referencial dos Estudos Culturais realizadas no CULT, apoiadas em ferramentas conceituais de Michel Foucault no período de 2010 a 2014.

Câncer corpo e cinema: lições de Hollywood sobre adoecer e morrer ${ }^{\text {(11) }}$ propôs conhecer o modo pelo qual o corpo do doente com câncer é apresentado nos filmes produzidos em Hollywood que abordam personagens adultos com câncer em estágio avançado. Com base nos Estudos Culturais, em sua vertente pós-estruturalista, o texto mostra como a mídia ensina a olhar e cuidar do doente de câncer desde que este descobre a doença até sua morte. A partir da análise cultural, sustentada pelas noções de discurso e subjetividade, propostas pelo filósofo Michel Foucault, a autora construiu três lições de Hollywood sobre adoecer e morrer, nelas mostrou como o cinema, na qualidade de instância educativa exerce uma verdadeira pedagogia cultural que produz sujeitos que veem o corpo doente de determinado modo, que ensina a cuidar desse corpo e a morrer de câncer, nos dando pistas sobre como aprendemos a nos relacionar com a doença a partir dos artefatos midiáticos ${ }^{(11)}$.

Eu decido meu fim?: a mídia e a produção de sujeitos que governam sua morte ${ }^{(12)}$, teve por objetivo analisar como os discursos que circulam em revistas informativas brasileiras propõem um modo de governo do final da vida, ou seja, tratam da produção de sujeitos que governam o seu fim. O corpus foi constituído por reportagens das revistas Veja e Isto É no período de 2002 a 2012, que foram analisadas com as ferramentas discurso, saber, poder e governo ${ }^{(12)}$. A mídia é apresentada como local de produção e de circulação de verdades que produzem o pensamento e as práticas sobre a morte no contemporâneo. O discurso médico 
sobressaiu-se como aquele autorizado a falar sobre esse evento, enquanto a enfermagem pouco apareceu nas reportagens e, quando aparece está atrelada aos cuidados corporais, sem ser citada sua posição estratégica nas políticas de cuidados paliativos e no domicílio. A morte no domicílio é apresentada como estratégia biopolítica produzida pelo Estado, estratégia que ganha legitimidade ao circular pelas páginas das revistas, sendo que a qualidade de vida na hora da morte aparece como disciplina a ser seguida ou como objetivo a ser alcançado. Assim, as revistas produzem o que chamamos de currículo do final da vida, ensinando e propagando a aceitação da morte, além de avaliar os leitores a partir de determinadas ferramentas que aferem sua capacidade de tomar decisões, como, por exemplo, a respeito da morte ${ }^{(12)}$.

Para estudar os dispositivos disciplinares utilizados por profissionais da enfermagem que atuam no Instituto Psiquiátrico Forense Doutor Mauricio Cardoso em Porto Alegre, elaborou-se a dissertação Entre o delito e a loucura: a enfermagem no manicômio judiciário(13). A autora inspirou-se na etnografia para produzir dados, analisando os mesmos através de dispositivos disciplinares utilizados pela instituição com objetivo de normalizar loucos criminosos, com a finalidade de torná-los aptos ao convívio social. A dissertação problematizou o trabalho dos(as) profissionais de enfermagem e mostrou a figura do louco criminoso como construção histórica, apontando que quando a enfermagem foi inserida neste espaço optou por seguir o discurso normalizador, repetindo o que faziam os(as) agentes prisionais. Os trabalhadores de enfermagem, que tiveram como "tutores" agentes penitenciários, conservam modelos desse trabalho quando ordenam e distribuem os espaços para controlar os corpos dos pacientes. Na pesquisa observou-se que a enfermagem passa a maior parte do tempo organizando e adestrando pacientes, esquadrinhando o tempo e o espaço para fabricar o tipo de paciente desejado pela Instituição, sendo tal prática pouco questionada pelos profissionais da enfermagem ${ }^{(13)}$.

$\mathrm{Na}$ tese de doutorado intitulada Melhor em casa? um estudo sobre atenção domiciliar ${ }^{(14)}$ foi problematizado o acontecimento da atenção domiciliar para conhecer os saberes e as condições de possibilidade que sustentam sua rede discursiva. O estudo, de inspiração genealógica, analisou documentos legais como: políticas públicas, decretos, portarias, resoluções que se referiram à atenção domiciliar em saúde, publicados no Diário Oficial da União, desde o início do século XX. As ferramentas foucaultianas utilizadas foram poder, governamento, biopolítica, saber, discurso, norma e dispositivo. Estas permitiram organizar unidades analíticas, quando foram estudadas as continuidades e descontinuidades que a atenção domiciliar apresentou no Brasil, especialmente no século XX. A tese analisou as diferentes políticas públicas, sendo a principal característica entre elas a descontinuidade, pois se o domicilio foi utilizado no início do século XX para isolar os doentes dos saudáveis, isso ocorreu devido as doenças transmissíveis que grassavam na época. Quando aconteceu a industrialização, no meio do século passado, e o trabalhador foi essencial para movimentar as máquinas, era necessário controlar as ausências no trabalho, já que com o advento do movimento sindical eles tinham adquirido o direito de adoecer. Assim, foi necessário que um agente estatal, no caso o médico, fosse aos domicílios para verificar as ausências do trabalhador. Ao analisar o momento atual, com o aumento das doenças crônico-degenerativas e a "crise" no hospital, o estudo apontou que a atenção domiciliar visa liberar leitos para a alta tecnologia, prestando atendimento ao paciente com condições crônicas ou incuráveis no domicílio. Nesse contexto emergiu a Estratégia de Saúde da Família, um instrumento da biopolítica, em que a enfermeira assume o papel de inspecionar, vigiar e controlar o paciente e a família (re)produzindo um governo da população proposto pelas políticas do Ministério da Saúde ${ }^{(14)}$. Ao longo das analises, a tese demonstrou que a prioridade das políticas de atenção domiciliar não foram as pessoas, mas a Economia ${ }^{(14)}$.

\section{口 PALAVRAS FINAIS}

Nossa proposta ao refletir sobre este modo de construir o conhecimento foi apontar outros modos de olhar para os objetos de pesquisa na área de enfermagem, colocando sob suspeita determinadas verdades, muitas vezes vistas como indiscutíveis em nosso campo de estudos. O pensamento do filósofo Michel Foucault e os Estudos Culturais apresentam como característica comum uma abertura do pensamento. Cabe salientar que tal característica, a possibilidade de articular Estudos Culturais com as questões da saúde, tem possibilitado lidar com uma gama ampliada de instituições, práticas e produções em operação nas sociedades atuais, permitindo refletir os efeitos de tais artefatos sobre os sujeitos que nelas vivem ${ }^{(5)}$. Estes e outros trabaIhos produzidos por nosso grupo de pesquisa têm olhado para artefatos culturais, tais como mídias, imagens e manuais, apontando que seus discursos pretendem conduzir condutas e determinar modos de vida.

A trajetória dessa perspectiva teórico metodológica foi sendo construída pela insatisfação com os limites disciplinares, propondo a interface entre as diferentes disciplinas, configurando um campo onde elas se conectam, 
estudando aspectos culturais da sociedade, considerando especialmente sua determinação histórica. Por outro lado, ao se ocupar com uma multiplicidade de objetos de investigação, os Estudos Culturais se ocupam com analises das relações de poder, apresentando diferentes aspectos da cultura, aqui vista como um modo de vida. Acreditamos que as palavras têm história, produzem determinados sentidos e efeitos que, no caso das mídias, podem ser deduzidos pela analise textual dos discursos emitidos pelos próprios meios.

Convém destacar que este campo de estudos interessa sobremaneira a área da saúde, já que pode ampliar a gama de problematizações que matizam e complexificam os debates sobre saúde. Deste modo, diferentes políticas, artefatos e discursos que circulam na área podem ser problematizados e constituídos como objetos de estudos sob uma ótica cultural, produzindo análises que produzem significados, imersos em redes de poder e verdade, em discursos que circulam e legitimam determinadas representações sobre como ser doente ou sadio, como ser pai ou mãe, como ser cuidador ou profissional de saúde.

Pensamos que as produções do CULT têm possibilitado outros e novos olhares sobre assuntos tais como o câncer, a morte, a loucura e a atenção domiciliar, promovendo analises culturais que exercitam a crítica e mobilizam conceitos que as atualizam possibilitando novas formas de pesquisar.

\section{口EFERÊNCIAS}

1. Costa MV, Silveira RH, Sommer LH. Estudos culturais, educação e pedagogia. Rev Bras Educ. 2003 [citado 2016 dez 15];(23):36-61. Disponível em: http://www. scielo.br/pdf/rbedu/n23/n23a03.
2. Johnson R. 0 que é, afinal, estudos culturais? In: Johnson R, Escosteguy AC, Schulman N, organizadores. 0 que é, afinal, estudos culturais? Belo Horizonte: Autêntica, 1999. p. 7-131.

3. Nelson C, Treichler PA, Grossberg L. Estudos culturais: uma introdução. In: Silva TT, organizador. Alienígenas na sala de aula: uma introdução aos estudos culturais em educação. 2. ed. Petrópolis: Vozes; 1998. p. 7-38

4. Hall S. A centralidade da cultura: notas sobre as revoluções culturais do nosso tempo. Educ Realidade 1997 [citado 2016 nov 22];22(2):15-46. Disponível em: http://www.seer.ufrgs.br/educacaoerealidade/article/view/71361.

5. Wortmann ML, Costa MV, Silveira RMH. Sobre a emergência e a expansão dos estudos culturais em educação no Brasil. Educação. 2015 [citado 2016 nov 20];38(1):32- 48. Disponível em: http://revistaseletronicas.pucrs.br/0js/index. php/faced/article/view/18441

6. Veiga-Neto A. Michel Foucault e os estudos culturais. In: Costa MV, organizador. Estudos culturais em educação: mídia, arquitetura, brinquedo, biologia, literatura, cinema... Porto Alegre: Ed. UFRGS; 2000. p. 37-69.

7. Fernandes CA. Discurso e sujeito em Michel Foucault. São Paulo: Intermeios; 2012.

8. Padilha, MICS. Mancia JR. Florence Nightingale e as irmãs de caridade: revisitando a história. Rev Bras Enferm. 2005 nov [citado 2016 nov 15];58(6):723-6. Disponivel em: http://www.scielo.br/pdf/reben/v58n6/a18v58n6.pdf.

9. Cordeiro FR. Kruse MHL. A produção do currículo do final da vida por meio do dispositivo pedagógico da mídia. Interface. 2015 dez;19(55):1193-1205. doi: http://dx.doi.org/10.1590/1807-57622014.0199.

10. Foucault M. Arqueologia do saber. Rio de Janeiro: Forense Universitária; 1986.

11. Niemeyer F. Kruse MHL. Dying with cancer: Hollywood lessons. Rev Gaúcha Enferm. 2013 Dec 34(4):161-9. doi: http://dx.doi.org/10.1590/S198314472013000400021.

12. Cordeiro FR. Kruse MHL, A produção do currículo do final da vida por meio do dispositivo pedagógico da mídia. Interface. 2015[citado 2016 Nov 14];19(55):1193-205. Disponível em: http://4www.redalyc.org/articulo. oa? $\mathrm{id}=180142194016$.

13. Cicolella DA. Entre o delito e a loucura: a enfermagem em manicômio judiciário [dissertação]. Porto Alegre (RS): Escola de Enfermagem, Universidade Federal do Rio Grande do Sul; 2014.

14. Oliveira SG. Melhor em casa? Um estudo sobre a atenção domiciliar [tese]. Porto Alegre (RS): Escola de Enfermagem, Universidade Federal do Rio Grande do Sul; 2014

\section{Autor correspondente:}

Maria Henriqueta Luce Kruse

E-mail:kruse@uol.com.br
Recebido: 06.07.2017

Aprovado: 20.10.2017 